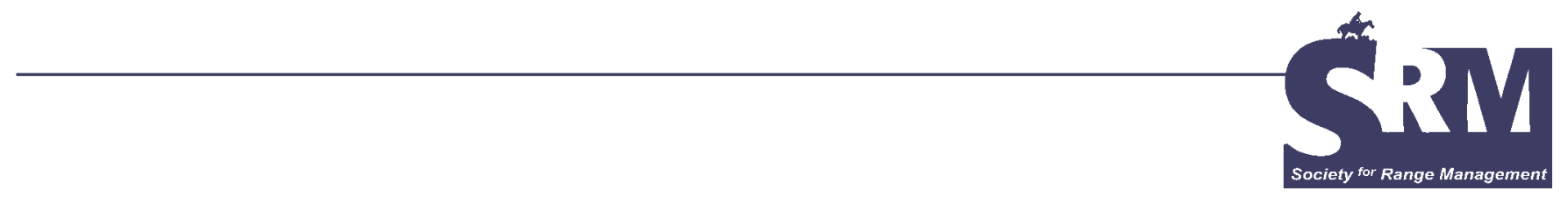

\title{
Grassbanks: Bartering for Conservation
}

\section{By Stephanie Lynn Gripne}

\section{Introduction}

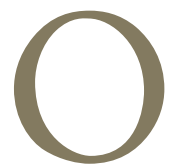

ver the next 10 years, the Shoshone National Forest in Wyoming will implement fuel-reduction burns on approximately 10 cattle grazing allotments, temporarily displacing up to 13 ranchers from 1 to 3 years. As is the case for many other national forests, a significant obstacle facing federal land managers implementing restoration treatments is the lack of alternative forage for permittees who must remove their livestock from allotments for extended time periods while restoration work occurs. If these temporarily displaced families sold their ranches, which are often large intact tracts of land adjacent to the national forest, there would likely be an increased rate of subdivision contributing to the loss of open space, wildlife habitat, and degradation of forest ecosystem processes such as fire. ${ }^{1,2}$ To help support restoration activities on public land and minimize the threat of habitat fragmentation on private land, the Wyoming Chapter of The Nature Conservancy (TNC) has used an irrigated pasture of its Heart Mountain Ranch near Cody as a grassbank to provide forage for permittees whose grazing allotments are temporarily unavailable because of the restoration activities on the Shoshone National Forest.

Grassbanking is a conservation tool that exchanges forage for conservation benefits. In the example of Heart Mountain Ranch, TNC trades forage for a suite of restoration activities. Fuel loads have been reduced (thus decreasing the potential for catastrophic fire), forage quality and quantity have been enhanced and increased for both cattle and wildlife, and the likelihood of habitat fragmentation has been temporarily reduced because ranches remain economically viable and intact.

\section{History of Grassbanking}

The term "grassbank ${ }^{\mathrm{TM}}$ " was coined and registered as a trademark by the Malpai Borderlands Group, a nonprofit organization located in Arizona devoted to restoring and maintaining "the natural processes that create and protect a healthy, unfragmented landscape to support a diverse, flourishing community of human, plant, and animal life in our Borderlands Region." The Malpai Borderlands Group, working on the 321,000-acre Gray Ranch, which is located in New Mexico and owned by the Animas Foundation, has developed several conservation tools, with grassbanking among their most innovative. The term "grassbank" was used to describe the practice where a rancher in need of alternative forage because of drought, or the desire to conduct restoration activities that require temporary cessation of grazing, moved the displaced cattle to the Gray Ranch. In exchange for forage, the rancher placed a permanent conservation easement on their property, which generally restricted development and, therefore, subdivision. The easement is held by the Malpai Borderlands Group, and its value is equal to the forage value the rancher used on Gray Ranch. As a result of this exchange of forage for conservation easements, over 25,000 acres have been restricted from subdivision. Many people associate grassbanking with conservation easements, but the Malpai Borderlands Group has been the only grassbank that has traded forage for conservation easements. All other grassbanks have traded forage for other types of conservation benefits, such as prescribed fire, rest, or wildlife habitat improvements.

While the term "grassbank" is relatively new, the practice of using a forage reserve, custom grazing, or other tools to incorporate rest rotation into a grazing management plan is 


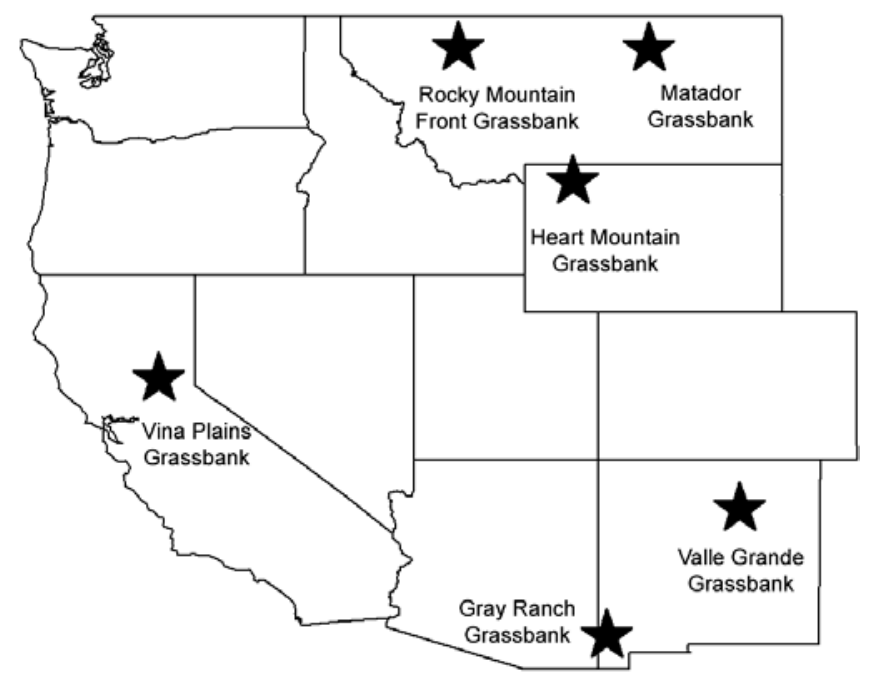

Figure 1. Location of grassbanks throughout the western United States.

centuries old, with examples found across the world, from Canada to Africa and New Zealand. ${ }^{3}$ In the United States, the historical precursors to grassbanks were "swing allotments," which were informally implemented by the USDA Forest Service in the first half of the 20th century. More recently, the Bureau of Land Management (BLM) and USDA Forest Service have informally supported similar tools, such as "reserve common allotments" and "forage reserves." Neither "swing allotments" nor "forage reserves" have been formally defined by the USDA Forest Service but are understood to be vacant allotments that can be used by operators in situations when their home allotment is unavailable for grazing for reasons such as rest, natural disasters, or management activities. The BLM has formally defined "reserve common allotments" as areas that allow permittees to engage in rangeland restoration by temporarily shifting their livestock to forage reserve areas. However, in 2004, the BLM chose not to formally adopt this tool. Regardless of the name, all these tools are an attempt to provide land managers flexibility, supporting a type of "third-party rest rotation" for managing their grazing operations in a way that produces both agricultural products and ecosystem goods and services over the long term.

\section{Existing Grassbanks}

Because of the perceived potential of grassbanks to help address numerous ecological problems in the western United States, significant amounts of time and money have been invested by organizations and individuals to develop grassbanks (Fig. 1). The 6 longest-running and most publicized include Malpai Borderlands-Gray Ranch Grassbank, Arizona; Valle Grande Grassbank, New Mexico; Vina Plains Lassen Foothills Grassbanki, California; Rocky Mountain Front Grassbank, Montana; Heart Mountain Grassbank, Wyoming; and Matador Ranch Grassbank, Montana. The Malpai Borderlands-Gray Ranch Grassbank was described previously; these 5 other most well-known grassbanks are described here. Over 17 additional potential grassbank initiatives have been documented as of $2001,{ }^{4}$ and additional grassbanks are emerging in Oregon, Nevada, South Dakota, Arizona, and New Mexico.

\section{Valle Grande Grassbank-Conservation Fundii}

In 1998, the Valle Grande Grassbank in New Mexico was formed when the Conservation Fund purchased 240 acres of base property associated with a 36,000-acre USDA Forest Service grazing allotment. The purpose of the grassbank has been the exchange of forage for restoration commitments (eg, riparian restoration, fire restoration, and removal of small diameter timber) by the USDA Forest Service on grazing allotments. ${ }^{5}$ This grassbank is primarily a public land grazing allotment that supports restoration work that occurs on other USDA Forest Service grazing allotments.

\section{Vina Plains Lassen Foothills Grassbank-TNC}

The Vina Plains Grassbank is owned and operated by a nonprofit organization that supports restoration work on private land. In 1997, the California Chapter of TNC converted its 4,600-acre Vina Plains Preserve into a grassbank to support some local landowners' interest in using prescribed burning to control invasive weeds on private land. The grassbank enabled local ranchers to undertake management practices that reduced the abundance of invasive species in exchange for reduced grazing fees at the preserve. ${ }^{6}$

\section{Rocky Mountain Front Grassbank-TNC}

The Rocky Mountain Front Grassbank in Montana is a 320acre parcel of private land. The local advisory group was enthusiastic about the Malpai Borderlands-Gray Ranch Grassbank model, but obtaining a large-acreage private ranch for the purpose of a grassbank was not monetarily feasible. Hence, the Rocky Mountain Front Grassbank started a small pilot grassbank on private land and intends to create a network of private grassbanks from ranches whose owners are willing to donate or lease forage, thereby forming a collective grassbank for use by local ranchers. ${ }^{7}$ In this case, both the grassbank and the restoration work take place on private land.

\section{Heart Mountain Grassbank-TNC}

The Heart Mountain Grassbank, located near Cody, Wyoming, is owned by the Wyoming Chapter of TNC. This 15,000-acre property includes 600 acres of low-elevation irrigated pasture that is utilized for the grassbank. Ranchers have used the grassbank when their federal grazing allotments are unavailable to them because of local USDA Forest Service and BLM restoration activities (eg, rest from graz-

\footnotetext{
${ }^{\mathrm{i}}$ At the time of publication, Vina Plains Grassbank was no longer operating. ii In November 2004, the Valle Grande Grassbank changed names to the Rowe Mesa Grassbank and is now associated with the Quivera Coalition.
} 
ing, prescribed burning). ${ }^{8}$ Heart Mountain Grassbank is the only grassbank that is utilizing irrigated pasture that is owned by a nonprofit organization, and it currently supports management activities on public land.

\section{Matador Ranch Grassbank-TNC}

The Montana Chapter of TNC owns and operates the Matador Ranch in eastern Montana as a grassbank. They use the forage on the 60,000 -acre ranch to leverage a variety of benefits, such as the conservation of prairie dogs, sage grouse, sod busting and weed prevention, and sustainable stewardship practices on both private and public land. ${ }^{9}$

\section{Grassbank Associated Research}

A decade ago, the term "grassbank" was virtually unknown. In recent years, the grassbank concept has gained momentum and has received increasing attention through numerous popular articles and unpublished scientific literature. ${ }^{10-15}$ However, no peer-reviewed literature exists describing or evaluating the effectiveness of grassbanks. The 3 primary descriptive sources of information about grassbanks are conference proceedings from a symposium held in New Mexico in 2001 titled "Grassbanks in the West: Challenges and Opportunities" and 2 Master's projects. ${ }^{11,12}$ The conference held in New Mexico included a diverse group of panelists addressing issues associated with grassbanks. The symposium was sponsored by the Quivira Coalition, the Conservation Fund, the Malpai Borderlands Group, the Northern New Mexico Stockman's Association, the USDA Forest Service, and New Mexico State University's Cooperative Extension Service. The conference provided clarification, assessment, and input about grassbanks and covered a variety of topics, including definitions, policy barriers, funding, and limitations of the concept.

While the conference provided the first public forum to clarify and assess grassbank initiatives, Claire Harper completed the first study of a grassbank, focusing on the Valle Grande Grassbank as a model for nonprofit organizations working in the arena of grazing on federal lands. ${ }^{16}$ She documented grassbank challenges, which included 1) the USDA Forest Service completing timely and high-quality environmental assessments similar to those of the National Environmental Policy Act, 2) the USDA Forest Service's development of restoration treatments to ensure a stable flow of participants, 3) obtaining long-term funding, 4) completing restoration treatments in a timely manner, and 5) increasing the role of rancher responsibility.

Edwards ${ }^{17}$ reviewed innovations related to conservation and focused specifically on grassbanks. She cautioned against the widespread endorsement of untested conservation strategies, including grassbanks, because such an endorsement could lead to the premature adoption of a conservation strategy that may not be sustainable. Edwards also noted that grassbanks will likely fail without support from public land management agencies and other pertinent institutions with authority to implement policies that enhance probabilities of grassbank success. ${ }^{17}$

Additional research is under way by this author and a team of ecologists, economists, and social scientists representing the University of Montana, the University of Idaho, Colorado State University, The Nature Conservancy, and the National Grassbank Network to address the effectiveness of grassbanking as a conservation tool (Gripne, unpublished data). This research will address questions such as the following: 1) Which grassbank institutional arrangements or models are associated with the least cost and greatest conservation benefits? 2) How can individuals involved with grassbanks economically value conservation benefits in order to ensure an even trade of forage for conservation benefit while avoiding private inurnment issues? 3) What are the biggest practical and policy challenges associated with grassbanking? 4) How do the different place-based grassbank initiatives (ie, Heart Mountain Grassbank in Cody, Wyoming) interact with the larger communities of interest (ie, citizens throughout the United States and the world with a vested interest in the Greater Yellowstone Ecosystem)? This research focuses on similarities and differences among currently operating grassbanks and opportunities to learn from those experiences.

\section{Challenges}

As with any conservation strategy, there are numerous ecological, economic, social, and policy challenges associated with grassbanks, chief among these being measuring and defining conservation benefits. Grassbanks are philosophically based on the concept of "quid pro quo" (ie, an equal value of forage is traded for an equal value of conservation benefits). Hence, grassbank participants should provide a measure of conservation benefit associated with restoration activities such as rest from grazing, reintroduction of historic fire regimes, and other specific activities. Grassbank participants must also calculate economic costs associated with achieving benefits. Once costs and benefits associated with grassbanking are known, stakeholders can address the critical question of whether the conservation benefits could be achieved at lower costs using alternative conservation strategies.

Valuing the conservation benefits associated with grassbanking in economic terms is essential to addressing the quid pro quo exchange requirement associated with grassbank operations. However, conservation valuation methods such as contingent valuation, hedonic, and substitution costs, and so on are often time intensive, costly, and controversial. While the notion of quid pro quo is philosophically tied to all grassbanks, this concept is a legal requirement of grassbanks operated by organizations with tax-exempt charitable status under US tax laws (eg, 501[c][3] organizations). In other words, such grassbanks must comply with operating rules established to ensure that tax-exempt organizations are operated for the charitable and public purposes for which 
they are established. Specifically, a charitable organization's assets cannot be used to benefit private individuals (ie, private inurnment).

Since a grassbank transaction is based on the concept of an exchange of forage for valuable and specific conservation benefits, the grassbank operator must ensure that the value of the conservation benefits are at least equal to the value of the forage exchanged. For example, if the nonprofit grassbank organization leases forage at a discounted rate to a rancher, it must demonstrate that the economic value of the conservation benefit achieved by the rancher equals or exceeds the value of discounted forage. The nonprofit grassbank organization would need to perform a market and/or nonmarket valuation of conservation benefits (ie, prescribed fire or reduced threat of habitat fragmentation from forfeited development rights) to demonstrate that the values of trade are equal. This task is further complicated when rights obtained from the landowner during the transaction also provide an economic benefit to the landowner (ie, if, by resting the landowner's pasture from grazing or by implementing fire program, certain invasive or exotic species are removed and result in an overall increase in the quality of the landowner's forage); adjustments must be made to account for those benefits.

A policy dilemma that may arise in grassbank transactions relates to the inability of the landowner to claim a charitable contribution deduction for the value of the standing grass. Under current tax law, an individual can donate cut grass in the form of baled hay to a nonprofit organization and deduct the value of the hay as a charitable donation. However, until the tax law is changed, a donation cannot be claimed for the same grass if it is standing. In addition, there are other policy issues specific to grassbanks that operate on public land. For example, restoration projects on public land require appropriate environmental assessments of the consequences of management activities under the National Environmental Policy Act, which has proven to be expensive and difficult to implement in a timely manner.

Finally, perhaps the greatest challenge associated with grassbanking is obtaining adequate funding and resources. Preliminary examination of existing grassbanks indicates that capital land investment ranges from $\$ 0$ to $\$ 8,000,000$ and that the annual operating costs associated with grassbanks range from $\$ 5,000$ to $\$ 260,000$. People who want to start a grassbank are logically seeking operational and financial resources that are currently unavailable to them in a central clearinghouse or network (Gripne, unpublished data). In response to this need, efforts are being made to establish initiatives such as a National Grassbank Network (http://www.grassbank.net) or Grassbank, Inc., to provide resources and representation for individual grassbanks.

\section{Conclusion}

Grassbanking is a tool that provides land managers with incentives and flexibility to pursue restoration activities that require temporary displacement of grazing activities that otherwise may not be feasible. Several grassbank initiatives have begun, and more are contemplated throughout the western United States. While there is a high level of enthusiasm among some land managers and conservation organizations for grassbanks, there are challenges associated with successfully developing grassbanks that remain to be solved. My preliminary research suggests that, in general, grassbanks require substantial financial and administrative resources to be committed over the duration of the project; these costs have, in several cases, proven to be greater than the stakeholders originally anticipated. Measuring conservation benefits and demonstrating associated economic values of those conservation benefits has proven technically difficult. The long-term success of grassbanking depends on how well managers and researchers address the practical and policy issues articulated herein related to grassbanks.

\section{Acknowledgments}

Jack Ward Thomas, Joni Ward, J. D. Wulfhorst, Hayley Hesseln, and Lisa Bay, Mike Dechter, Claire Harper, Bruce Runnels, Bill Miller, Tom Hobby, Ben Brown, Jill Belsky, and Meg Bishop provided valuable comments on this manuscript. Meg Bishop, Laura Bell, and Maria Sonnet provided invaluable support. I received financial and in-kind support from the Boone and Crockett Wildlife Conservation Program; the Wyoming, Montana, and California Chapters of The Nature Conservancy; the USDA Forest Service; the Bureau of Land Management; and a McIntire-Stennis grant. For a complete source of grassbank reading information, visit Stephanie Gripne's Grassbank Research Website Literature Section at $\mathrm{http} / / /$ compatibleventures.us. This article is dedicated in memory to my mom, Jan Bailey Gripne.

Author is Research Fellow, Boone and Crockett Wildlife Conservation Program, College of Forestry and Conservation, University of Montana, Missoula, MT 59812.

\section{References}

1. Thomas, J. W., And S. L. Gripne. 2002. Maintaining viable farms and ranches adjacent to national forests for future of wildlife and open space part 1: the history of the problem. Rangelands 24(1):10-13.

2. Maestas, J. D., R. L. Knight, And W. C. Gilgert. 2003. Biodiversity across a rural land-use gradient. Conservation Biology 17(5):1425-1434.

3. Fernández-Giménez, M. E., And D. M. Swift. 2003. Strategies for sustainable grazing management in the developing world. Proceedings of the VIIth International Rangeland Congress; 28 July-1 August 2003; Durban, South Africa. Durban, South Africa: International Rangelands Congress.

4. HARPER, C. 2001. The grassbank movement: A status report of grassbank initiatives in the West. Sante Fe, NM: Conservation Fund. 
5. DeBuys, W. Summer 1999. Growing credit at the Grassbank: collaboration at New Mexico's Valle Grande. Range Magazine:54-55.

6. McNutT, P. 2001. The Lassen Hills Vina Plains Grassbank. San Francisco, CA: The Nature Conservancy.

7. BAY, L. 2001. A case study of the Rocky Mountain Front Grassbank. Helena, MT: The Nature Conservancy of Montana.

8. BELL, L. 2001. A case study of the Heart Mountain Grassbank. Lander, WY: The Nature Conservancy of Wyoming.

9. Poole, L., And D. Veseth. 2003. Case study of the glaciated plains grassbank at the Matador Ranch. Helena, MT: The Nature Conservancy of Montana.

10. PAGE, J. 1997. Ranchers from a "radical center" to protect wideopen spaces. Smithsonian 28(3):50-60.

11. White, C. 19 September 1999. Conservation pays off for ranchers. Idaho Statesman:8B.
12. Goldman, D. 24 October 1999. "Radical center" responds to the extremes. Santa Fe Nerw Mexican: F7.

13. Jensen, M. N. 2001. Can cows and conservation mix? Bioscience 51(2):85-90.

14. Christensen, J. 10 September 2002. Environmentalists hail the ranchers: Howdy, pardners! New York Times:D3(N) pF3(L) col 2.

15. Kappel, T. Summer 2002. Ranching and Conservation on the Matador in Bigsky Landmarks. Montana Chapter of The Nature Conservancy Newsletter, p.16.

16. HARPER, C. L. 2002. "Invested partner": A new role for nonprofit organizations in U.S. federal land management. Project for the Master of Environmental Management degree in the Nicholas School of the Environment and Earth Sciences of Duke University, Durham, NC.

17. EDWARDS, C. 2002. Grassbanks: a study of policy diffusion and adaptation in the American West [master's thesis]. Boulder, CO: University of Colorado. 